\title{
An Economic Analysis of Micro and Small Manufacturing Enterprises in Nagaland
}

\author{
Medongulie Zatsu*1 and Y. Temjenzulu Jamir ${ }^{2}$ \\ ${ }^{1}$ Department of Economics, Phek Govt. College, Phek-797108, Nagaland, India \\ ${ }^{2}$ Department of Economics, Nagaland University, Lumami-798627, Nagaland, India \\ *Corresponding author: zmedongulie@yahoo.com
}

\begin{abstract}
Micro and Small manufacturing enterprises not only plays a critical role in providing employment opportunities at comparatively lower capital cost than large enterprises but also helps in rural industralisation and reduce regional disparities. This paper attempts to bring out an economic analysis of the manufacturing enterprises by studying the relationship between operating costs and the gross monthly income (GMI) and the mode of production. All the items of costs show a positive effect on GMI. The coefficient of determination or $\mathrm{R}^{2}$ is 0.87 and that an increase by one unit will have a positive impact on GMI by 304649 times. Using the Cobb-Douglas production function the study also finds that manufacturing units are operating under decreasing returns to scale, labour $\left(\aleph_{1}\right)$ and capital $\left(\aleph_{2}\right)$ equals to 0.93 and that given the two inputs, the additional capital input will be preferred to labour input because output elasticity of capital is higher than the output elasticity of labour.
\end{abstract}

Keywords: Manufacturing, gross monthly income.

Manufacturing enterprises is one of the most vital sectors of an economy in ensuring equitable, inclusive and employment friendly economic growth. It contributes to economic development by creating employment opportunities for rural and urban population, providing goods and services at affordable costs by offering innovative solutions and sustainable development to the economy as a whole. The growth in manufacturing output is an important determinant of both productivity growth and gross domestic product growth (McCausland and Theodossiou, 2012). Manufacturing has been important for growth in developing countries because structural and infrastructural bases are essential for balanced growth and there is always a linkage among all the sectors of the economy. Manufacturing enterprises play a very crucial role in socio-economic development of an economy on account of their advantages like lower capital, employment generation, decentralization of industrial activity and utilization of locally available resources. Manufacturing enterprises constitute an important and crucial segment of the industrial sector in the economy and by contributing to the overall growth of the gross domestic product, employment generation and exports, the sector has emerged as the engine of growth for the economy. In India as per micro, small and medium Enterprises Development Act 2006, manufacturing enterprises is defined as:

- A micro enterprise, where the investment in plant and machinery does not exceed twenty five lakh rupees.

- A small enterprise, where the investment in plant and machinery is more than twenty five lakh rupees but does not exceed five crore rupees.

- A medium enterprise, where the investment in plant and machinery is more than five crore rupees but does not exceed ten crore rupees.

The distribution of enterprises by nature of activity in the registered sector shows that in all the North eastern states of India, enterprises are highly 
concentrated in manufacturing/ assembly/processing which ranges from 68 percent to 96 percent whereas enterprises in services and repairing \& maintenance ranges 4 percent to 32 percent. Data for North eastern states indicates that 72.96 percent of enterprises are engaged in manufacturing/assembly/ processing enterprises, 14.66 percent of enterprises are engaged in service enterprises and 12.38 percent of enterprises are engaged in repairing \& maintenance enterprises. In Nagaland, 95.57 percent of enterprises are engaged in manufacturing/ assembly/ processing enterprises, 1.35 percent of enterprises are engaged in service enterprises and 3.08 percent of enterprises are engaged in repairing \& maintenance enterprises. As per the economic survey of Nagaland, manufacturing sector contribution to State GDP is 10.16 percent (Quick estimates of 2015-16).

The main objective of the paper is to analyse and compare the mode of production of micro and small manufacturing enterprises using the Cobb-Douglas production function. An attempt is also made to compare the income generated between the two categories i.e. micro and small enterprises. Data of 85 manufacturing enterprises were collected for the study but analyses for medium enterprises could not be done as there was only one unit.

\section{LITERATURE REVIEW}

Micro and small scale enterprises (MSEs) have been found to have locational flexibility. Uzor (2004) noted that MSEs could be more readily used to achieve industrial dispersal and regional balance in economic development. Of particular importance is small firms' usefulness in the diversification of the industrial structure and for the transformation of the rural economy. He further opined that micro and small scale enterprises (MSEs) contribute to national development by positively influencing the distribution of income both in functional terms, wages and profits in nominal terms. Focus on SMEs help to decentralize industries thereby not only accelerating rural development but also stemming urban immigration and the consequent problems of congestion in the cities.

Fabayo (1989) observed that one major claim for focus on SMEs is that they are large employers of labour and this makes them vital in coping with the problems of unemployment and poverty. According to him, strong evidences based on country and regional experiences exist to show that small firms are major source of employment opportunities for a wide cross-section of the workforce: the young, old part-time workers and the cyclically unemployed.

Meyanathan (1994); Ukpabio (2004) and the World Bank (2001), agreed that it is micro and small scale enterprises (MSEs) that play intermediate role in the development of large scale enterprises. They reduce regional disparities through the creation of employment opportunities in the rural areas and mobilize local resources more readily than largescale industries.

A production function is a physical relationship between input and output and it describes a frontier representing the limit of output obtainable from feasible combination of input. With the work of Charles W. Cobb and Paul H. Douglas in 1928, the history of production function took a new turn where by Cobb-Douglas type of production function has been estimated by agricultural economists for virtually any production process involving the transformation of inputs into outputs in an agricultural setting and economists have used Cobb-Douglas type of specification for virtually every conceivable type of production process. Using the production function, one can discuss changes in the supply-side performance on the basis of the observed simultaneous developments in the quantity of labour, capital and total factor productivity (Hajkova and Hurnik, 2007).

Humphrey (1997) remarked that fundamental to economic analysis is the idea of a production function. A production function is simply a set of recipes or techniques for combining inputs to produce output. Production functions apply at the level of the individual firm and at the macro economy at large. At the micro level, economists use production functions to generate cost functions and input demand schedules for the firm. The famous profit-maximising conditions of optimal factor hire derive from such micro-economic functions. At the level of macro economy, analysts use aggregate production functions to explain the determination of factor income shares and to specify the relative contributions of technological progress and expansion of factor supplies to economic growth. 
Hossain and Islam (2013) analysed the manufacturing sector of the south-west region and use CobbDouglas Production function to estimate the productivity, allocative efficiency and measuring returns to scale. The study showed that cement, jute and textile manufacturing firms have decreasing return to scale whereas fertilizers and seafood processing firms have increasing return to scale. The Study further showed that in the estimated value of marginal productivity and allocative efficiency, labour productivity of all sorts of manufacturing firms is greater than the capital productivity.

Prajneshu (2008) made a fitting of Cobb-Douglas Production Function by first linearizing the models through logarithmic transformation and then applying method of least squares. Naqvi and Ashfaq (2013) and Memon et al. (2016) had use Cobb-Douglas production involving various production associated factors while analysing the total production of maize on farms.

Miller (2008) pointed out that there does not appear to be overwhelming evidence that would lead one to choose the CES over the Cobb-Douglas for forecasting GDP and income shares. When empirical estimates are restricted to the Cobb-Douglas form, the fit tends to be quite good.
Josheski et al. (2011) argued that one of the most commonly used production function by economists is Cobb-Douglas production function which represents a simple production function that gives a responsible description of actual economies. Cobb-Douglas production function provides an opportunity to establish the participation of certain factors of production in creating the total output in the economy.

\section{FINDINGS}

\section{(I) Startup capital}

The total investment made in 85 manufacturing units is ₹ 2348.05 lakhs with an average startup capital of ₹ 27.62 lakhs per unit. The distribution of investment shows that on an average micro enterprises account for 5.35 lakhs, small enterprises 69.17 lakh and medium enterprises 750 lakhs.

\section{(II) Monthly operating costs}

Expenditure are funds used by an enterprise to attain new assets and improve existing ones. In other words, expenditure is payments for necessary inputs in the operations of the business. Expenditure is classified as wages, rent, electricity, raw materials, transportation and miscellaneous.

Table 1: Startup Capital (₹ in Lakhs)

\begin{tabular}{cccc}
\hline Category & No. of Units & Investment & Avg. Investment \\
\hline Micro enterprise & $66(77.65)$ & $353.05(15.34)$ & 5.35 \\
Small enterprise & $18(21.18)$ & $1245(53.02)$ & 69.17 \\
Medium enterprise & $1(1.18)$ & $750(31.94)$ & 750 \\
\hline Total & $\mathbf{8 5}$ & $\mathbf{2 3 4 8 . 0 5}$ & $\mathbf{2 7 . 6 2}$ \\
\hline
\end{tabular}

Source: Field survey; ${ }^{*}$ Figure in parenthesis indicates percentage.

Table 2: Monthly operating cost

\begin{tabular}{|c|c|c|c|c|}
\hline \multirow{3}{*}{ Items of expenditure } & Micro enterprises & Small enterprises & Medium enterprises & Total \\
\hline & $\mathrm{N}=66(77.64)$ & $\mathrm{N}=18$ (21.18) & $\mathrm{N}=1$ (1.18) & \multirow{2}{*}{$\mathrm{N}=85$} \\
\hline & $\mathrm{E}=158(30.92)$ & $E=349(68.30)$ & $E=4(0.78)$ & \\
\hline Wages & 1027786 (30.03) & $2379000(69.50)$ & $16000(0.47)$ & 3422786 (16.55) \\
\hline Rent & 202052 (59.31) & $133589(39.22)$ & $5000(11.47)$ & $340641(1.65)$ \\
\hline Electricity & $87550(5.74)$ & $1437200(94.26)$ & - & 1524750 (7.38) \\
\hline Raw materials & $5547500(48.63)$ & 5840000 (51.19) & $20000(0.18)$ & $11407500(55.17)$ \\
\hline Transportation & $666500(27.96)$ & $1697500(71.20)$ & $20000(0.84)$ & $2384000(11.53)$ \\
\hline Miscellaneous & $430900(27.00)$ & $1165000(73.00)$ & - & $1595900(7.72)$ \\
\hline Total & 7962288 & 12652289 & 61000 & 20675577 \\
\hline
\end{tabular}

* Figure in parenthesis indicates percentage; NB: N= Number of observations, E= Employment. 
The total monthly expenditure in manufacturing sector is ₹ 2,05,65,577 of which wages is ₹ $34,22,786$ (16.55 percent), rent is ₹ $3,40,641$ (1.65 percent), electricity is ₹ $15,24,750$ (7.38 percent), raw materials is ₹ $1,14,07,500$ (55.17 percent), transportation is ₹ $23,84,000$ (11.53 percent) and miscellaneous is ₹ $15,95,900$ (7.72 percent). Among the items of expenditure, raw material is the single largest item of expenditure followed by wages and transportation.

Wages: Out of the total expenditure on wages which is ₹ $34,22,786$, micro enterprise accounts for 30.03 percent with an average wage of ₹ 6504.98 , small enterprise 69.50 percent with an average wage of ₹ 6816.62 and medium enterprise 0.47 percent with an average wage of $₹ 4000$ per unit.

Rent: Out of the total expenditure on rent which is ₹ 3,40,641, micro enterprise accounts for 59.31 percent with an average of $₹ 3061.39$ per unit, small enterprise 39.22 percent with an average rent of ₹ 19084.14 per unit and medium enterprise 11.47 percent with an average rent of ₹ 5000 per unit.

Electricity: Out of the total expenditure on electricity which is ₹ $15,24,750$, micro enterprise accounts for 5.74 percent with an average of ₹ 1326.52 per unit and small enterprise 94.26 percent with an average of ₹ 205314.29 per unit.

Raw materials: Out of the total expenditure on raw materials which is $₹ 1,14,07,500$, micro enterprise accounts for 48.63 percent with an average of ₹ 84053.03 per unit, small enterprise 51.19 percent with an average of ₹ 324444.44 per unit and medium enterprise 0.18 percent with an average of $₹ 20000$ per unit.

Transportation: Out of the total expenditure on transportation which is ₹ $23,84,000$, micro enterprise accounts for 27.96 percent with an average expenditure of $₹ 4772.73$ per unit, small enterprise 71.20 percent with an average of ₹ 94305.56 per unit and medium enterprise 0.84 percent with an average of ₹ 20000.

Miscellaneous: Out of the total expenditure on miscellaneous which is ₹ $15,95,900$, micro enterprise accounts for 27.00 percent with an average of ₹ 6528.79 per unit and small enterprise 73.00 percent with an average of ₹ 64722.22 per unit.

\section{(III) Gross Monthly Income (GMI)}

Manufacturing sectors generate a total monthly income of ₹ 2,35,16,152 (Rupees two crore thirtyfive lakhs sixteen thousand one hundred and fiftytwo). The annual gross income generated by the 85 manufacturing units thus comes to ₹ $28,21,93,824$ (twenty-eight crore twenty-one lakhs ninety three thousand eight hundred and twenty-four). Micro enterprises account 39.78 percent of the GMI, small enterprises 59.75 percent and medium enterprises 0.47 percent of GMI.

Table 3: Distribution of GMI (in ₹)

\begin{tabular}{cccc}
\hline Category & Units & GMI & Average. \\
\hline Micro enterprise & $66(77.64)$ & $9354863(39.78)$ & 141740.35 \\
Small enterprise & $18(21.18)$ & $\begin{array}{c}14050289 \\
(59.75)\end{array}$ & 780571.61 \\
& & $111000(0.47)$ & 111000.00 \\
$\begin{array}{c}\text { Medium } \\
\text { enterprise }\end{array}$ & $1(1.18)$ & & \\
\hline Total & $\mathbf{8 5}$ & $\mathbf{2 3 5 1 6 1 5 2}$ & $\mathbf{2 7 6 6 6 0 . 6 1}$ \\
\hline
\end{tabular}

* Figure in parenthesis indicates percentage.

The correlation between manufacturing sector and GMI is found to be $\mathrm{r}=0.93$ which indicates that there is a high degree of positive relationship. It means that as the number of unit increases, GMI also increases. At the level of significance alpha $=0.05$, the result shows that correlation is not significant since the estimated $t$-value is lower than the table value. The coefficient of determination or $R^{2}$ is 0.87 indicating that 87 percent of the variation on GMI is caused by change in units. To see the effect of units on GMI, the regression equation shows:

$$
\begin{gathered}
Y=a+b X \\
Y=-793015+304649 X
\end{gathered}
$$

Where, $\mathrm{Y}$ is the dependent variable (GMI) and $\mathrm{X}$ is the independent variable (units). This shows that an increase in a unit of enterprise will have a positive impact on GMI by 304649 times. And since the estimated t-value is lower than the table value, it is statistically not significant.

In micro enterprises, the coefficient of correlation is $\mathrm{r}=0.99$ indicating a high degree of positive relationship. The value $\mathrm{R}^{2}=0.99$ demonstrates that 99 percent of the variation on GMI is explained by the units. The calculated $t$-value is higher than the table value and therefore, is statistically significant at 5 percent. The effect of units on GMI in this sector 
Table 4: Relationship between units and GMI

\begin{tabular}{|c|c|c|c|c|c|c|c|}
\hline \multirow[t]{2}{*}{ Category-wise } & \multicolumn{2}{|c|}{ Correlation } & \multicolumn{4}{|c|}{ Regression } & \multirow[b]{2}{*}{$N$} \\
\hline & $r$ & $t$ & $R^{2}$ & $a$ & $b$ & $S E$ & \\
\hline Micro enterprise & 0.99 & $20.64^{*}$ & 0.99 & -1146131 & 193837 & 9393 & 66 \\
\hline Small enterprise & 0.98 & 5.04 & 0.96 & 876774 & 634443 & 125961 & 18 \\
\hline
\end{tabular}

Note: ${ }^{*}$ and ${ }^{* *}$ sign indicates 5 percent and 1 percent significance level; $a=$ constant, $b=$ beta, $S E=$ Standard Error, $N=$ number of observations.

Table 5: Regression results of GMI and items of expenditure

\begin{tabular}{cccc}
\hline Variables & $\begin{array}{c}\text { Overall } \\
\text { Coefficients }\end{array}$ & $\begin{array}{c}\text { Micro enterprise } \\
\text { Coefficients }\end{array}$ & $\begin{array}{c}\text { Small enterprise } \\
\text { Coefficients }\end{array}$ \\
\hline Constant & $13677.64(3.15)$ & $11202.65(2.13)$ & $19164.14(1.15)$ \\
Wages $\left(X_{1}\right)$ & $0.99\left(12.40^{* * *}\right)$ & $0.91\left(5.34^{* * *}\right)$ & $0.96\left(7.75^{* * *}\right)$ \\
Rent $\left(X_{2}\right)$ & $0.98(1.21)$ & $1.56(1.08)$ & $0.39(0.16)$ \\
Electricity $\left(X_{3}\right)$ & $1.17\left(16.69^{* * *}\right)$ & $6.54\left(2.53^{*}\right)$ & $1.20\left(8.92^{* * *}\right)$ \\
Raw material $\left(X_{4}\right)$ & $1.06\left(34.83^{* * *}\right)$ & $1.00\left(14.94^{* * *}\right)$ & $1.07\left(24.87^{* * *}\right)$ \\
Transportation $\left(X_{5}\right)$ & $0.93\left(20.11^{* * *}\right)$ & $1.18\left(3.66^{* *}\right)$ & $0.92\left(17.28^{* * *}\right)$ \\
Miscellaneous $\left(X_{6}\right)$ & $1.55\left(16.10^{* * *}\right)$ & $1.00\left(2.62^{*}\right)$ & $1.59\left(14.12^{* * *}\right)$ \\
$\mathrm{R}^{2}$ & 0.99 & 0.96 & 0.99 \\
$\mathrm{~N}$ & 85 & 66 & 18 \\
\hline
\end{tabular}

Note: (i) Figure in parenthesis indicates t-value, (ii) $N=$ No. of observations (iii) *,** and *** sign indicates 10 percent, 5 percent and 1 percent significance level.

shows that there is a positive impact on GMI by 193837 times and since the $b$ coefficient is positive, it indicates that an increase in unit is related to GMI. Similarly, in small enterprises, $\mathrm{r}$ is 0.98 indicating a high degree of positive correlation between units and GMI and since the calculated $\mathrm{t}$-value is lower than the table value, the effect is not significant but the $b$ coefficient is positive, therefore, it can be concluded that an increase in the number of units is related to GMI.

\section{(IV) Regression Analysis}

A regression analysis is carried out to find the relationships between the output (Gross Monthly Income) and the various costs involved in the process of production in manufacturing sector.

The variables affecting total output is expressed in the form of equation as:

$$
Y=f\left(X_{1^{\prime}}, X_{2^{\prime}} \ldots, X n\right)
$$

Where, $Y=$ Output, $X_{1}=$ Wages, $X_{2}=$ Rent, $X_{3}=$ Electricity, $X_{4}=$ Raw material, $X_{5}=$ Transport and $X_{6}=$ Miscellaneous

The regression analysis of GMI with cost variables is analyzed and interpreted from the table 4 . In the overall analysis, all variables show expected sign which is having a positive effect on GMI. That is, a 10 percent increase in all the given variables will increase GMI by 9.9 percent $\left(X_{1}\right), 9.8$ percent $\left(X_{2}\right)$, 11.7 percent $\left(X_{3}\right), 10.6$ percent $\left(X_{4}\right), 9.3$ percent $\left(X_{5}\right)$ and 15.5 percent $\left(X_{6}\right)$ respectively. As shown in the regression result, the overall coefficient of determination is $\mathrm{R}^{2}=0.99$, for micro enterprises $R^{2}=0.96$ and for small enterprises $R^{2}=0.99$ which implies that 1 percent, 4 percent and 1 percent of the variation in the dependent variable correspondingly is not explained by the given independent variables. Under the micro enterprises, all variables show expected sign which is having a positive effect on GMI. That is, a 10 percent increase in all the given variables will increase GMI by 9.1 percent $\left(X_{1}\right), 15.6$ percent $\left(X_{2}\right), 65.4$ percent $\left(X_{3}\right), 10$ percent $\left(X_{4}\right), 11.8$ percent $\left(X_{5}\right)$ and 10 percent $\left(X_{6}\right)$ respectively.

Under the small enterprises, the regression equations with all variables show expected sign which is having a positive effect on GMI showing that a 10 percent increase in all the given variables will increase GMI by 9.6 percent $\left(X_{1}\right), 3.9$ percent $\left(X_{2}\right)$, 12 percent $\left(X_{3}\right), 10.7$ percent $\left(X_{4}\right), 9.2$ percent $\left(X_{5}\right)$, and 15.9 percent $\left(X_{6}\right)$ respectively. 


\section{(V) Cobb-Douglas Production function}

For this analysis, the Cobb-Production function is given as:

$$
\mathrm{Q}(\mathrm{L}, \mathrm{K})=\mathrm{AL} \mathrm{L}^{\mathrm{B1}} \mathrm{K}^{\beta 2}
$$

Where, $\mathrm{Q}=$ Gross monthly income, $\mathrm{A}=$ Total factor productivity which is constant and independent of labour and capital, L= Labour input, $\mathrm{K}=$ Capital input, $B_{1}=$ Output elasticity of labour, $B_{2}=$ Output elasticity of capital

Here $A, B_{1}$ and $\beta_{2}$ are the unknown parameters.

Since, equation (i) is not a linear equation, the natural $\log$ is used to convert the equation into linear equation. Therefore, equation (i) can be rewritten as

$$
\begin{aligned}
& \ln (\mathrm{Q})=\ln (\mathrm{A})+\mathrm{B}_{1}{ }^{*} \ln (\mathrm{L})+\mathrm{B}_{2}{ }^{*} \ln (\mathrm{K})+\mathrm{e}^{t} \\
& \ln (\mathrm{Q})=\ln (\mathrm{A})+\mathrm{B}_{1}{ }^{*} \ln (\mathrm{L})+\mathrm{B}_{2}{ }^{*} \ln (\mathrm{K}) \\
& =1.414422+0.16^{*} \ln (\mathrm{L})+0.77^{*} \ln (\mathrm{K})
\end{aligned}
$$

From the above equation, the output elasticity of labour $\left(\beta_{1}\right)$ and capital $\left(\beta_{2}\right)$ is 0.16 and 0.77 respectively. In other words, if labour input is increased by 10 percent, output will increase by an estimated 1.6 percent holding capital input constant and holding labour constant, 10 percent increase in capital would increase 7.7 percent of output. This result shows that there is decreasing returns to scale since $B_{1}+\beta_{2}=0.93$ is less than 1 and given the two inputs, the additional capital input will be preferred to labour input because output elasticity of capital is higher than the output elasticity of labour. The $\mathrm{R}^{2}$ value 0.99 means that 99 percent of the variation in the output is explained by labour and capital.

In micro enterprises, the output elasticity of labour $\left(B_{1}\right)$ and capital $\left(\beta_{2}\right)$ is 0.14 and 0.77 respectively which indicates that if labour input is increased by 10 percent, output will increase by an estimated 1.4 percent holding capital input constant and holding labour constant, 10 percent increase in capital would increase 7.7 percent of output exhibiting a decreasing returns to scale. The value of $R^{2}=0.97$ indicates 97 percent of the variation in the output is explained by labour and capital.

In small enterprises, the output elasticity of labour $\left(B_{1}\right)$ and capital $\left(B_{2}\right)$ is 0.19 and 0.71 respectively which indicates that if labour input is increased by 10 percent, output will increase by an estimated 1.9 percent holding capital input constant and holding labour constant, 10 percent increase in capital would increase 7.1 percent of output exhibiting a decreasing returns to scale. The value of $R^{2}=0.99$ indicates 99 percent of the variation in the output is explained by labour and capital.

The calculated F-statistic is 0.000635 which is lower

Table 6: Cobb-Douglas production function and covariance

\begin{tabular}{cccc}
\hline \multicolumn{4}{c}{ Estimated Cobb-Douglas Production Function and Covariance } \\
\cline { 3 - 4 } Variable & Overall & Micro & Category \\
\hline Coefficient & $1.414422(9.77)$ & $1.506575(6.01)$ & $1.780602(7.96)$ \\
Labour & $0.167567(8.15)$ & $0.146584(4.67)$ & $0.196906(7.32)$ \\
Capital & $0.77121(43.29)$ & $0.779636(38.35)$ & $0.718034(26.42)$ \\
Labour x labour & 1.457728 & 0.59436 & 1.1636 \\
Capital x capital & 1.942913 & 1.41498 & 1.13995 \\
Labour x capital & 1.249453 & 0.50261 & 0.89266 \\
$\mathrm{R}^{2}$ & 0.99 & 0.97 & 0.99 \\
Adj. $\mathrm{R}^{2}$ & 0.984923 & 0.973766 & 0.993581 \\
$\mathrm{~N}$ & 85 & 66 & 18 \\
\hline & & & $0.001769\left(3.68^{*}\right)$ \\
\hline Overall & F test & $0.001806\left(3.15^{*}\right)$ & $0.554282\left(4.49^{*}\right)$ \\
Labour & $0.000635\left(3.15^{*}\right)$ & $1.225382\left(4.001^{*}\right)$ & $0.069744\left(4.49^{*}\right)$ \\
\hline Capital & $0.475359\left(4.001^{*}\right)$ & $0.048259\left(4.001^{*}\right)$ &
\end{tabular}

Note: (i) Figure in parenthesis indicates t-value, (ii) \# sign indicates critical F-value (iii) N= No. of observations (iv) There is one medium enterprise. 
than the critical F-value of 3.15. Similarly, the estimated F-value in both labour and capital is lower than the critical F-value of 4.001. The calculated $F$ value in micro enterprise and small enterprise at 0.002 each is lower than the critical F-value of 3.15 and 3.68 respectively, and also the calculated $\mathrm{F}$ values for labour and capital is lower than the critical $F$ values.

It may be noted that the output elasticity of capital is higher than the output elasticity of labour in all respect. It is observed that capital plays a more important role in the additional output and hence, concludes that manufacturing sector is capital intensive.

\section{CONCLUSION}

Manufacturing enterprises play a very crucial role in socio-economic development of an economy on account of their advantages like lower capital, employment generation, decentralization of industrial activity and utilization of locally available resources. With the decline in agricultural labourers along with relatively high growth of urban population over the past decade in Nagaland, manufacturing enterprises will come to play a crucial role in generating income and employment in both rural and urban areas. There are evidences that non-farm activities (forest and mineral based) are gaining prominence in rural areas especially those that are in close proximity to towns. Availability of raw materials, relatively cheaper labour, low capital and better infrastructure has contributed in establishing small and micro manufacturing enterprises in rural areas.

\section{REFERENCES}

Fabayo, J.A. 1989. “Small-Scale Enterprise Development Strategy: A Critical Option for Long-Term Economic Progress in Nigeria". The India Journal of Economics, 58: 159-171.

Hajkova and Hurnik, J. 2007. “Cobb Douglas Production Function: The Case of a Converging Economy", Czech Journal of Economics and Finance, 57(9-10): 465-476.
Hossian, M.S. and Islam, A.K.M.N. 2013. "Productivity Analysis and Measuring the Returns to Scale of Manufacturing Firms in the South-West Region of Bangladesh". IOSR Journal of Humanities and Social Science (IOSR-JHSS) 17(1): 69-80.

Humphrey, T.M. 1997. “Algebraic Production Functions and Uses Before Cobb-Douglas", Federal Reserve Bank of Richmond Economic Quarterly, 83/1: 51-83.

Josheski, D. and Lazarov, D. and Koteski, C. 2011. “CobbDouglas production function revisited, VAR and VECM analysis and a note on Fischer/Cobb-Douglass paradox" MPRA Paper No. 33576. https://mpra.ub.uni-muenchen. de/33576/

McCausland, David, W. and Loannis Theodossiou, 2012. Is manufacturing still the engine of growth? Journal of Post Keynesian Economics, 35(1).

Meyanathan, S.D. 1994. "Industrial Structures and the Development of Small and Medium Enterprise Linkages: Examples from East Asia". The World Bank.

Miller, E. 2008. “An Assessment of CES and Cobb-Douglas Production Functions". Congressional Budget Office. www.cbo.gov.

Nagaland Economic Survey, 2015-16. Department of Economics and Statistics, Government of Nagaland.

Prajneshu 2008, "Fitting Cobb-Douglas Production Functions: Revisited", Agricultural Economics Research Review, 21: 289-292.

Ukpabio, S.A. 2004. "Development of Small Scale Sector, What Role for the Federal Government Nigerian Banker", 17(1).

Uzor, O.O. 2004. Small and Medium Scale Enterprises Cluster Development in South-Eastern Region of Nigeria. Institute for World Economics and International Management, pp. 5-15. 
